\title{
Prevalence of Early Childhood Caries and Its Associated Risk Factors Among Preschool Children in Sousse: A Cross-Sectional Survey
}

\author{
Mohamed Ali Chamli' Farah Chouchene ${ }^{2}$ Imene Benzineb Taher ${ }^{3}$ \\ Fatma Masmoudi ${ }^{2}$ Ahlem Baaziz ${ }^{2}$ Fethi Maatouk ${ }^{2}$ Hichem Ghedira ${ }^{2}$
}

'Pediatric and Preventive Dentistry Department, Hospital La Rabta, Faculty of Dental Medicine of Monastir, Laboratory of Biological, Clinical and Dento-Facial Approach, University of Monastir, Monastir, Tunisia

2Pediatric and Preventive Dentistry Department, Clinic of Dental Medicine, Faculty of Dental Medicine of Monastir, Laboratory of Biological, Clinical and Dento-Facial Approach, University of Monastir, Monastir, Tunisia

${ }^{3}$ Department of General Medicine, Primary care Hospital El Alaa,

Kairouan, Faculty of Medicine Sousse, Tunisia

\author{
Address for correspondence: Farah Chouchene, Pediatric and \\ Preventive Dentistry Department, Clinic of Dental Medicine, Faculty of \\ Dental Medicine of Monastir, Rue Hedi Chekir, Hiboun 5111 Mahdia, \\ Monastir, Tunisia \\ E-mail: farah.pedo@gmail.com
}

\begin{abstract}
Objective: This study aimed to assess the prevalence and associated risk determinants of early childhood caries (ECC) among preschool children living in rural and urban communities of the main region of Sousse (Tunisia).

Materials and Methods: In this cross-sectional survey, 200 preschool children aged between 1-5 years living in Sousse, Tunisia were randomly recruited using a three-stage clustered sampling technique. The "dmft" index according to the WHO $1997 \mathrm{crite}-$ ria was used to assess ECC. Questionnaire including sociodemographic characteristics, dietary and oral hygiene behaviors were completed by the parents and the dental examination of children was conducted by one investigator. The statistical associations of variables with ECC and dmft were evaluated by Pearson chi-square test.

Results: A total of 3974 primary teeth were examined. The prevalence of ECC was $45 \%$ and the mean dmft was 4.17 . From the children who had ECC, $96.5 \%$ were untreated. Children aged 5 years had the highest (37.5\%) prevalence of ECC and the association between dental caries and age was statistically significant $(P<0.05)$. There was a tendency toward high caries in children of low and modest socio-economic status $(P<0.05)$. Frequency of tooth cleaning other than using fluoridated toothpaste significantly increased the prevalence of ECC $(\mathrm{P}<0.05)$.
\end{abstract}

Conclusion: The early identification of poor oral hygiene and improper feeding habits should be considered in preventive health promotion in low and modest socioeconomic communities of Sousse, Tunisia.

Keywords: Early childhood caries, prevalence, preschool child, risk factors

How to cite this article: Chamli MA, Chouchene F, Benzineb Taher I, Masmoudi F, Baaziz A, Maatouk F, Ghedira H. Prevalence of Early Childhood Caries and Its Associated Risk Factors Among Preschool Children in Sousse: A Cross-Sectional Survey. J Pediatr Dent 2020;6(2):39-45 


\section{Introduction}

According to the American Academy of Pediatric Dentistry (AAPD), early childhood caries (ECC) which is considered today as one of the most frequent oral disease in children, is defined as the presence of one or more decayed (non-cavitated or cavitated lesions), missing (due to caries), or filled tooth surfaces in any primary tooth in child at $\leq 71$ months of age.[1]

The American Dental Association recognizes that ECC is a significant public health problem and urges the health professionals and the public to acknowledge that a child's teeth are susceptible to decay as soon as they begin to erupt.[2]

The etiology of this complex multifactorial disease is the combination of frequent consumption of fermentable carbohydrates as drinks, especially when a baby is sleeping, with on-demand breast or bottle feeding, oral colonization by cariogenic bacteria (especially Streptococcus mutans), poor oral hygiene and poor parenting. $[3,4]$

This chronic, transmissible disease can result in considerable pain, suffering, reduction of the quality of life of affected children and may compromise their permanent dentition. [4] Furthermore, the treatment of ECC is very costly, time consuming, and in most cases, it requires full dental rehabilitation under general anesthesia by a pediatric dentist, however, following restoration of decayed teeth, recurrence of decay and its complications are very common in the absence of adequate prevention programme and follow- up visits.[5]

Prevention of ECC can be achieved by; the education of prospective and new parents, the identification of "high risk" children, the use of preventive agents and the teaching of good oral hygiene practice. $[4,6]$

Although, the prevalence of this condition is considered as high, there is a very limited data on its prevalence among preschool children in Tunisia.

The aim of this study was to assess the prevalence and associated risk determinants of ECC among preschool children living in rural and urban communities of the main region of Sousse (Tunisia).

\section{Materials and Methods}

\section{Ethical approval}

Ethical approval was obtained from the Preventive Dentistry Committee, and visitations permissions with the schools were obtained from the Regional
Delegation of the Ministry of Family and Child Welfare (Tunisia).

\section{Study design and population}

A descriptive cross-sectional study, carried out in the rural and urban communities of the main region of Sousse (Tunisia) from October to December 2019, was used to determine the prevalence of ECC in preschool children.

The simple size was determined using the following formula $n=Z^{\wedge} 2(P)(1-P) / d 2$, were $Z=1.96$ is the confidence level for an accuracy of $0.05, p=17 \%$ is the prevalence of ECC according to similar epidemiological survey conducted in Sudan [7], d=0.05 correspondents to the chosen accuracy. Accordingly, a simple size of 200 children was sought.

The cluster sampling technique was applied to select the study population. A three-stage clustered sampling technique was used. In the first stage, the selected district was stratified into urban and rural areas. In the second stage, of 40 kindergarten stratified by district, 10 were randomly selected. In the third stage, 20 children were selected in each institution.

Only children under the age of six with primary dentition enrolled in the selected kindergarten present at the time of the study and whose parents signed a written consent were included in the present study.

Children with mixed dentition, who were absent during the dental examination and whose parents did not consent to their children's participation were excluded.

\section{Data collection}

After obtaining the ethical approval, the selected schools were officially informed, and a written consent were obtained from children's parents after a coordination with the school principals to arrange a day for dental examination.

A questionnaire was designed to record personnel profile of the children. The questionnaire included information on the following: sociodemographic characteristics (sex, age, residence, and family income and the mother's level of education), children's general health (gestational age, and child's body mass index (BMI)), dietary behaviors (feeding history, frequency of sweets consumption, and snaking), oral hygiene behaviors (daily brushing frequency, toothbrush renewal frequency, and using fluoride toothpaste).

All children received oral hygiene instructions and oral hygiene hamper which consisted of toothpaste and a toothbrush. 
After the children had brushed their teeth under a dentist's supervision, oral examinations were performed by one previously trained and standardized dentist, using a mouth mirror and periodontal probe under natural light with the examiner standing and the child seated. No radiographs were taken. The $\mathrm{dmft}$ index according to the WHO 1997 criteria was used to assess ECC.[8]

ECC was defined as the presence of 1 or more decayed, missing or filled tooth surfaces in any primary tooth in a child aged up to and including 71 months of age. The findings were recorded by the same examiner on an individual clinical chart for each child. The children who required dental treatment were referred to the Primary Health Hospitals and children who required interceptive orthodontic treatment were referred to the Pediatric Dentistry Department at clinic of Dental Medicine of Monastir.

\section{Statistical analysis}

Statistical analyses were performed using SPSS version 22.0 (IBM corp. Statistical Package for Social Sciences for Windows, Armonk, NY, USA).
Descriptive statistics and frequencies were generated. Chi-square test was used to assess the difference between more than two groups. Student's t-test was used for comparison between continuous variables. The level of statistical significance was set at $0.05 \%$.

\section{Results}

A total of 200 children aged between 1-5 years, with a mean age of $4.44 \pm 0.77$ years; were enrolled in this crosssectional study. A total of 3974 primary teeth were examined.

The prevalence of ECC of the whole sample of 200 children was $45 \%$ and the mean $\mathrm{dmft}$ was 4.17 . From the children who had ECC $96.5 \%$ were untreated.

Out of the 200 children examined, 120 (60\%) were boys and $80(40 \%)$ were girls.

The prevalence of ECC according to sociodemographic characteristics are shown in Table1.

Most of the study participants (58.5\%) were in the age of 5 years, and the prevalence of ECC increased with age. Children aged 5 years had the highest $(37.5 \%)$ prevalence of ECC and the association

Table 1. Children's demographic and socioeconomic characteristics and ECC prevalence

\begin{tabular}{|c|c|c|c|c|c|}
\hline & n (\%) & No. with ECC & No. with no ECC & Mean DMFT (SD) & $\mathbf{p}$ \\
\hline \multicolumn{6}{|l|}{ Gender } \\
\hline Boys & $120(60 \%)$ & $53(26.5 \%)$ & 67 (33.5\%) & $2.91(3.06)$ & 0.349 \\
\hline Girls & $80(40 \%)$ & 37 (18.5\%) & $43(21.5 \%)$ & $1.26(2.44)$ & \\
\hline \multicolumn{6}{|l|}{ Age } \\
\hline $1-2$ years & $3(1.5 \%)$ & $00(00 \%)$ & $3(1.5 \%)$ & $00(00)$ & $\underline{0.003}$ \\
\hline 3-4 years & $80(40 \%)$ & $15(7.5 \%)$ & 65 (32.5\%) & $0.73(1.37)$ & \\
\hline 5 years & 117 (58.5\%) & 75 (37.5\%) & $42(12 \%)$ & $0.22(2.22)$ & \\
\hline \multicolumn{6}{|l|}{ Residence } \\
\hline Urban & $100(50 \%)$ & 38 (19\%) & $62(31 \%)$ & $1.26(2.44)$ & 0.261 \\
\hline Rural & $100(50 \%)$ & $52(26 \%)$ & $48(24 \%)$ & $2.91(3.06)$ & \\
\hline \multicolumn{6}{|l|}{ Family income } \\
\hline Modest & $120(60 \%)$ & 65 (32.5\%) & $55(27.5 \%)$ & $2.91(3.06)$ & $\underline{0.004}$ \\
\hline Mean/easy & $80(40 \%)$ & 25 (12.5\%) & $55(27.5 \%)$ & $1.26(2.44)$ & \\
\hline \multicolumn{6}{|l|}{ Gestational age } \\
\hline Full term & 195 (97.5\%) & 87 (43.5\%) & 108 (54\%) & $3.26(3.33)$ & 0.361 \\
\hline Premature & $5(2.5 \%)$ & $3(1.5 \%)$ & $2(1 \%)$ & $1.07(0.9)$ & \\
\hline Post-term & $00(00)$ & $00(00)$ & $00(00)$ & $00(00)$ & \\
\hline \multicolumn{6}{|l|}{ Body mass index } \\
\hline Underweight & $8(4 \%)$ & $4(2 \%)$ & $4(2 \%)$ & $0.54(1.06)$ & 0.563 \\
\hline Normalweight & 191 (95.5\%) & 85 (42.5\%) & $106(53 \%)$ & $2.91(3.06)$ & \\
\hline Overweight & $1(0.5 \%)$ & $1(0.5 \%)$ & $00(00)$ & $0.04(1.26)$ & \\
\hline
\end{tabular}


Table 2. Distribution of ECC according to children's dietary habits

\begin{tabular}{|c|c|c|c|c|c|}
\hline & n (\%) & No. with ECC & No. with no ECC & DMFT Mean (SD) & $\mathbf{p}$ \\
\hline \multicolumn{6}{|l|}{ Feeding history } \\
\hline Breast only & $120(60 \%)$ & $35(17.5 \%)$ & $85(42.5)$ & $1.91(3.06)$ & 0.614 \\
\hline Breast and bottle & $60(30 \%)$ & $45(22.5 \%)$ & $15(7.5 \%)$ & $2.54(1.66)$ & \\
\hline Bottle only & $20(10 \%)$ & $10(5 \%)$ & $10(5 \%)$ & $1.33(2.32)$ & \\
\hline \multicolumn{6}{|l|}{ Sweet consumption } \\
\hline$<3$ days/week & $19(9.5 \%)$ & $5(2.5 \%)$ & $14(7 \%)$ & $0.07(1.92)$ & 0.534 \\
\hline $3-4$ & $42(21 \%)$ & $15(7.5 \%)$ & $27(13.5 \%)$ & $1.63(2.06)$ & \\
\hline$>4$ & $139(69.5 \%)$ & $70(35 \%)$ & $69(34.5 \%)$ & $2.99(3.09)$ & \\
\hline \multicolumn{6}{|l|}{ Snacking } \\
\hline$<3$ days/week & $19(9.5 \%)$ & $5(2.5 \%)$ & $14(7 \%)$ & $0.07(1.92)$ & 0.534 \\
\hline $3-4$ & $42(21 \%)$ & $15(7.5 \%)$ & $27(13.5 \%)$ & $1.63(2.06)$ & \\
\hline$>4$ & $139(69.5 \%)$ & $70(35 \%)$ & $69(34.5 \%)$ & $2.99(3.09)$ & \\
\hline
\end{tabular}

between dental caries and age was statistically significant $(\mathrm{p}<0.05)$.

The socio-economic status was based on the combination of the mother's level of education and the family income. The children were divided into two groups based on this and there was a tendency toward high caries in children of modest socio-economic status with statistically significant association $(\mathrm{p}<0.05)$.

The prevalence of ECC according to dietary habits are summarized in Table 2.

About 120 (60\%) of the examined children were exclusively breastfed, only 20 (10\%) were bottle fed and the rest 60 (30\%) were both breast and bottle-fed. There was higher caries prevalence among children who were both breast and bottle-fed with no statistically signifi- cant difference in the three methods of infant feeding with regards to the prevalence of ECC among the children $(\mathrm{p}>0.05)$.

About $70 \%$ of the children had snacks in-between their meals and had been given a form of sweet or sugar with a higher prevalence of ECC among these children but no statistically significant association between the frequency of consumption of sweets and occurrence of ECC ( $>0.05)$ were found.

The prevalence of ECC according to hygiene habits are shown in Table 3.

About 94 children (47\%) did never brushed their teeth, 68 (34\%) children had their teeth brushed less than once a day, and only $5(1.5 \%)$ children had their teeth brushed 3 times a day. There was a statistically sig-

Table 3. Distribution of ECC according to Children's oral hygiene behaviors

\begin{tabular}{|c|c|c|c|c|c|}
\hline & n (\%) & No. with ECC & No. with no ECC & Mean DMFT (SD) & $\mathbf{p}$ \\
\hline \multicolumn{6}{|c|}{ Daily brushing frequency } \\
\hline 3 times/day & $3(1.5 \%)$ & $00(00)$ & $3(1.5 \%)$ & $00(00)$ & $\underline{0.011}$ \\
\hline Twice daily & $17(8.5 \%)$ & $4(2 \%)$ & $13(6.5 \%)$ & $0.08(1.54)$ & \\
\hline Once daily & $18(9 \%)$ & $5(2.5 \%)$ & $13(6.5 \%)$ & $0.15(1.36)$ & \\
\hline Less than once daily & $68(34 \%)$ & $29(14.5 \%)$ & $39(19.5 \%)$ & $0.58(2.04)$ & \\
\hline Never & $94(47 \%)$ & $52(26 \%)$ & $42(21 \%)$ & $3.09(4.29)$ & \\
\hline \multicolumn{6}{|c|}{ Toothbrush renewal frequency } \\
\hline$<3$ months & $27(13.5)$ & $10(5 \%)$ & $17(8.5 \%)$ & $0.30(2.72)$ & 0,521 \\
\hline 3-6 months & $64(32 \%)$ & $42(2 \%)$ & $22(11)$ & $0.25(2.33)$ & \\
\hline$>6$ months & $109(54.5 \%)$ & $38(19 \%)$ & $71(35.5 \%)$ & $1.53(2.66)$ & \\
\hline \multicolumn{6}{|l|}{ Fluoride toothpaste } \\
\hline Yes & $100(50 \%)$ & $38(19 \%)$ & $62(31 \%)$ & $1.26(2.44)$ & 0.261 \\
\hline No & $100(50 \%)$ & $52(26 \%)$ & 48 (24\%) & $2.91(3.06)$ & \\
\hline
\end{tabular}

Underlined values indicate a $p$ value less than 0.05 
nificant association between the teeth brushing frequency and the occurrence of ECC $(\mathrm{p}<0.05)$.

\section{Discussion}

Despite the importance of ECC among young children, only a few articles published in Tunisia studying the prevalence of ECC were found.[9]

In, the present study, a high prevalence of ECC (45\%) among preschool children aged between 1 and 5 years living in Sousse was reported. This high prevalence remains considerably lower than that described in other studies. In fact, a study conducted on 546 Moroccan preschool children showed an ECC prevalence of $74.2 \%$ and severe-ECC prevalence of 47.3\%.[10]

Due to the differences in the studies' design, and other related variables, comparing the present survey findings to previous global and national studies was difficult.

According to a recent systematic review aimed to describe the dental caries situation of preschool children living in 16 countries from six continents, the prevalence of ECC ranged from $22.5 \%$ in India to $90 \%$ in Indonesia.[11]

In the present study, the prevalence of dental caries increased with age and became significantly higher by the time child reached 5 years of age, which was in accordance with other studies reporting similar results. $[12,13]$ In fact, as children grow older there is a change in the dietary habits and hygiene practices, leading to the increase in dental caries, and an increased number of erupted primary teeth which becomes more exposed to the oral environment and cariogenic challenges.[12]

A tendency toward high caries in children of modest socio-economic status with statistically significant association $(\mathrm{p}<0.05)$ were reported. Indeed, many studies confirmed the strong associations between ECC and socio-economic groups.[14]

ECC is normally present in children who are born in poor-economic conditions, born in a single parent home, or with low educated parents, especially uneducated mothers.

Other studies stated that children in low-income families have four times higher primary decayed-missing- filled teeth $(\mathrm{dmft})$ scores than children in highincome families.[15]

In fact, Socio- economic conditions can strongly influence health literacy which in turn also have an impact on general health.

Children who live in poor economic conditions don't make their dental visits frequently until dental problems occur, or at an older age. [16,17]
The present study showed that children who were residing in rural areas presented a greater prevalence of ECC in comparison to those residing in urban areas, but the difference was not statistically significant. Similar studies showed similar results and explained that high level of ECC among children residing in rural areas was due to the isolation from urban centers, restricted or inadequate knowledge regarding oral health care and inefficient bacterial control practices.[12,18,19]

In the present study, the prevalence of caries in the children with no brushing group was significantly higher than in those children who brushed their teeth two times a day which was in accordance with studies done by Soroye and Braimoh [20], Veiga et al[21] Parasuraman et al[22], and Sharma et al[12] who reported that increased frequency of tooth brushing is an important determinant in decreasing the prevalence of dental caries and mean DMFT in children. This suggests that tooth brushing with a frequency of at least twice a day may spare the teeth from developing caries by removing dental plaque more effectively and decreasing the risk of caries among children.

Children who used toothbrush and fluoridated toothpaste had a significantly lower prevalence of caries when compared with children who did not use fluoridated toothpaste. It is worthy to note that most of the parents in this study were not familiar with the difference in toothpaste content and many did not know the effect of fluoride content in the toothpaste on their children's teeth. In most cases the parents used the same toothpaste, which they were using for themselves for their children.[23]

Neonatal and infancy risk factors such as birth prematurity were not significantly associated with the ECC in this study which disagreed with others study showing that prematurely born individuals have poor mineralization of the teeth and poorer oral health indicators, supporting the evidence of the role played by enamel defects in the development of ECC. Thus, perinatal factors such as low birth weight and gestational prematurity are risk factors for the development of early childhood caries.[24]

An important finding of this study was the low number of filled teeth, indeed from the children who had ECC, 96.5\% were untreated which showed a lack of awareness about oral health among parents. Lack of accessibility and affordability for oral health care seems to be a less probable reason as Sousse city has many dental institutions which offer treatment at low costs for the lower socio-economic status population.[25] 
In order to decrease the prevalence of ECC, more oral health programmes focusing on mothers, caregivers, community health workers, preschool teachers and children should be implemented in our communities.[26]

The importance of first dental visit, diet counseling, and proper oral care methods should be stringently advocated to expectant parents, new parents and preschool teachers and caregivers to inculcate lasting oral health attitudes among children.[17]

\section{Conclusion}

This study reported a high prevalence of ECC among preschool children living in rural and urban communities of the main region of Sousse which confirm that there is an urgent need to implement preventive and curative oral health programs for these preschool children.

\section{Financial Disclosure: Nil.}

Conflict of Interest: None declared.

\section{References}

1. American Academy of Pediatric Dentistry. Policy on Early Childhood Caries (ECC): Classifications, Consequences, and Preventive Strategies. Pediatr Dent 2016;38(6):52-54

2. American Dental Association. Statement on Early Childhood Caries [Internet]. Available at: https:/www.ada.org/en/ about-the-ada/ada-positions-policies-and-statements/statement-on-early-childhood-caries Accessed November 2020

3. O'Keefe E. Early childhood caries. Evid Based Dent 2013;14(2):4041 doi:10.1038/sj.ebd.6400928

4. Kowash MB. Severity of early childhood caries in preschool children attending Al-Ain Dental Centre, United Arab Emirates. Eur Arch Paediatr Dent 2015;16(4):319-324 doi:10.1007/s40368-0140164-6

5. O'Sullivan EA, Curzon ME. The efficacy of comprehensive dental care for children under general anesthesia [published correction appears in Br Dent J 1991 Sep 7;171(5):122] Br Dent J 1991;171(2):56-58 doi:10.1038/sj.bdj.4807603

6. Köhler B, Bratthall D, Krasse B. Preventive measures in mothers influence the establishment of the bacterium Streptococcus mutans in their infants. Arch Oral Biol 1983;28(3):225-231 doi:10.1016/0003-9969(83)90151-6

7. Awooda E, Saeed SM, Elbasir EI. Caries prevalence among 3-5 years old children in Khartoum State - Sudan. Innov J Med Health Sci (IJMHS) 2013;3(2):42-44

8. World Health Organization. Oral health surveys: basic methods [Internet]. World Health Organization; 1997 Available at: https://apps.who.int/iris/handle/10665/41905 Accessed November 2020
9. Maatouk F, Ghedira P, Ghnim D, Jmour P, Jaafoura D. Oral health survey in Tunisian preschool children. Dental News 2002;9(4):35-37

10. Mtalsi M, Oumensour K, Chlyah A, Aljalil Z, Choukir M, Agoujjim S, El Arabi S. Assessment of the impact of severe early childhood caries on the quality of life of preschool children and their parents. J Pediatr Dent 2020;6(1):20-25

11. Chen KJ, Gao SS, Duangthip D, Lo ECM, Chu CH. Prevalence of early childhood caries among 5-year-old children: A systematic review. J Investig Clin Dent 2019;10(1):e12376 doi:10.1111/ jicd. 12376

12. Sharma K, Gupta KK, Gaur A, Sharma AK, Pathania V, Thakur VB. A cross-sectional study to assess the prevalence of early childhood caries and associated risk factors in preschool children in district Mandi, Himachal Pradesh. J Indian Soc Pedod Prev Dent 2019;37(4):339-344 doi:10.4103/JISPPD. JISPPD_95_18

13. Goel P, Sequeira P, Peter S. Prevalence of dental disease amongst 5-6 and 12-13 year old school children of Puttur municipality, Karnataka State-India. J Indian Soc Pedod Prev Dent 2000;18(1):11-17

14. Colak H, Dülgergil CT, Dalli M, Hamidi MM. Early childhood caries update: A review of causes, diagnoses, and treatments. J Nat Sci Biol Med 2013;4(1):29-38 doi:10.4103/09769668.107257

15. Zafar S, Harnekar SY, Siddiqi A. Early childhood caries (ECC): aetiology, clinical considerations and consequences and management. Int Dent Australas Ed 2009;11(4):24-36

16. Tsai AI, Chen CY, Li LA, Hsiang CL, Hsu KH. Risk indicators for early childhood caries in Taiwan. Community Dent Oral Epidemiol 2006;34(6):437-445 doi:10.1111/j.16000528.2006.00293.x

17. Kuriakose S, Prasannan M, Remya KC, Kurian J, Sreejith KR. Prevalence of early childhood caries among preschool children in Trivandrum and its association with various risk factors. Contemp Clin Dent 2015;6(1):69-73 doi:10.4103/0976237X.149295

18. Irigoyen ME, Luengas IF, Yashine A, Mejía AM, Maupomé G. Dental caries experience in Mexican schoolchildren from rural and urban communities. Int Dent J 2000;50(1):41-45 doi:10.1111/j.1875-595x.2000.tb00545.x

19. Perinetti G, Varvara G, Esposito P. Prevalence of dental caries in schoolchildren living in rural and urban areas: results from the first region-wide Italian survey. Oral Health Prev Dent 2006;4(3):199-207

20. Soroye MO, Braimoh BO. Oral health practices and associated caries experience among secondary school students in Lagos State, Nigeria. J Oral Res Rev 2017;9:16-20

21. Veiga N, Pereira C, Amaral O. Prevalence and determinants of dental caries in a sample of schoolchildren of Sátão, Portugal. Rev Port Estomatol Med Dentária e Cir Maxilofac 2014;55(4):214219 doi:https://doi.org/10.1016/j.rpemd.2014.10.004

22. Parasuraman G, Gowtham Krishna Y, Kaviya M, Jain NA, Rajendiran P, Dutta R. A study on the prevalence of dental 
caries among the school-going children in Tamil Nadu. Int J Community Med Public Health 2017;4(10):3582-3589

23. Olatosi OO, Inem V, Sofola OO, Prakash P, Sote EO. The prevalence of early childhood caries and its associated risk factors among preschool children referred to a tertiary care institution. Niger J Clin Pract 2015;18(4):493-501 doi:10.4103/11193077.156887

24. dos Santos Junior VE, de Sousa RM, Oliveira MC, de Caldas Junior AF, Rosenblatt A. Early childhood caries and its relationship with perinatal, socio-economic and nutritional risks: a cross-sectional study. BMC Oral Health 2014;14:47 Published 2014 May 6. doi:10.1186/1472-6831-14-47

25. Yavagal PC, Velangi CS, Singh I, Desai P, Sunny CH. Prevalence of early childhood caries among children attending anganwadis in Davangere City: A cross sectional survey. J Indian Assoc Public Health Dent 2020;18:199-203

26. Kumarihamy SL, Subasinghe LD, Jayasekara P, Kularatna SM, Palipana PD. The prevalence of Early Childhood Caries in 1-2 yrs olds in a semi-urban area of Sri Lanka. BMC Res Notes 2011;4:336 doi:10.1186/1756-0500-4-336 